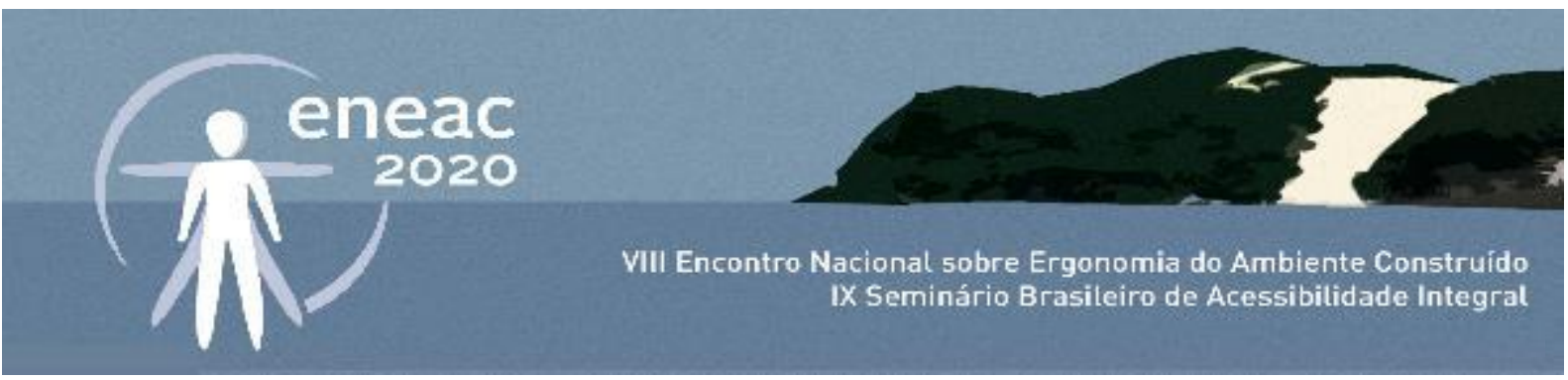

\title{
Os desafios da mobilidade urbana no desenho das cidades
}

\section{The challenges of urban mobility in the design of cities}

\author{
PAULA TELES \\ Engenheira, Mestre, Membro do Instituto de Cidades e Vilas com Mobilidade (ICVM PT), \\ do Instituto de Cidades e Vilas com Mobilidade - Brasil (ICVM BR) e do \\ Instituto de Cidades de Excelência de España (ICEE); paulateles@mobilidadept.com
}

\section{RESUMO}

\section{A necessidade de planear a mobilidade}

De forma muito clara, há muito poucos hábitos associados à atitude de planear e, no entanto, o exercício de planear é, talvez, o único que nos poderá levar à sustentabilidade das cidades. 0 planeamento pressupõe um processo, não é uma atitude de projeto, que se faz na hora. É algo que tem uma premissa muito relevante: o fator tempo.

No planeamento clássico, esse tempo tinha um período maior, mais estável, o mundo era menos veloz e essa atitude de planear podia durar décadas. Hoje, não é assim. Os ciclos políticos são reduzidos e, esse é, um dos problemas que impede a atitude ágil e rápida de introduzir o planeamento na gestão e na decisão. De resto, por vezes, há políticos que até medo têm de falar na palavra "plano", justamente, pela má memória associada aos problemas temporais da elaboração dos atuais instrumentos de planeamento obrigatórios, que, por esse modo, trazem tempos congelados às dinâmicas hoje necessárias nos territórios em desenvolvimento.

Assim, ao invés dos Planos "tradicionais", os Planos de Mobilidade Urbana Sustentável (PMUS) terão de ser mais flexíveis e dinâmicos para serem também mais ágeis no apoio à decisão política. $\mathrm{A}$ ausência da sua elaboração poderá, em muitos casos, levar a despesas inconsequentes e a resultados irreversíveis. Mas só será viável se cada município desenvolver o seu, o que não está a acontecer. Este documento, obrigatório em quase todos os países da Europa, dota as autarquias e seus territórios de um documento estratégico, integrador, articulado e coerente, que possibilite tornar consequentes as ações e os investimentos. 


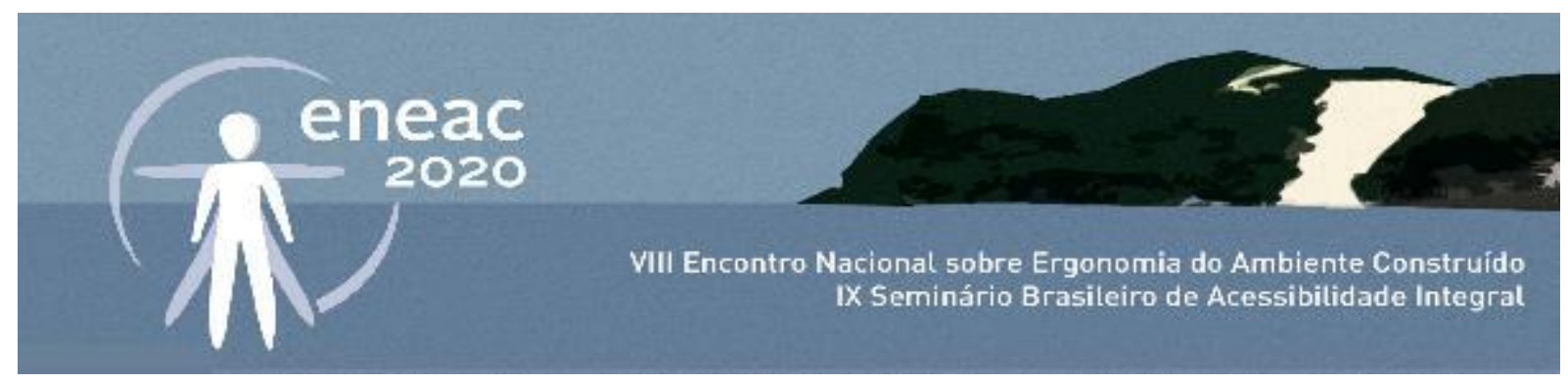

Em síntese, planar a mobilidade urbana é, hoje, identificar os problemas e as fragilidades que agitam as cidades, e, de forma holística, tentar integrar todas as variáveis no desenvolvimento de dois grandes objetivos: a saúde pública e a qualidade de vida urbana dos cidadãos.

As grandes infraestruturas, as grandes estradas, os grandes parques de estacionamento subterrâneos, viadutos, túneis, etc., desenvolveram-se, essencialmente, na década 80 e parte da 90 e esta constituiu a primeira geração do planeamento. Mais tarde, na segunda geração, para além de investirem ainda nos modos rodoviários, investiram-se noutros layers de mobilidade, como as redes cicláveis, os percursos pedestres, a acessibilidade e mobilidade para todos, os transportes públicos, a logística, etc. Mas importa salientar que um número elevado de cidades europeias já se encontram na terceira geração do Planeamento da Mobilidade Urbana. Estas cidades, apresentam a multimodalidade como o foco da mobilidade. Não é o layer que assume a importância setorial mas o nó dos layers, as ligações e os interfaces. Esta terceira geração de Planos foca a estratégia na "pessoa", cada vez com mais diversos padrões de mobilidade utilizados nas diferentes cadeias de deslocação diária, desde o veículo rodoviário, ao transporte público e passando muito mais pelos modos suaves, como andar de bicicleta ou a pé. Esta mudança de cultura de mobilidade exige, assim, uma cidade mais desenhada, mais articulada nos diversos sistemas de tarifários, bilhética e informação online, em que o MAAS, mobilidade enquanto serviço, os sharings, etc., vão ser, sem dúvida, o caminho do futuro. A cidade deixa de ser desenhada apenas para carros e o seu foco é transferida pelo peão enquanto prioridade essencial de deslocação. E o espaço público passa a ter de ser mais importante na vida da cidade, capaz de voltar a ser um palco de mobilidades, vivências urbanas, aproximação de pessoas, lugar de estadia e de relações. Ou seja, nesta nova geração de planeamento da mobilidade as grandes infraestruturas são repensadas e algumas delas são mesmo anuladas ou reutilizadas em novas funções, como é o caso paradigmático da Hight Line, em Nova lorque, uma linha de caminho de ferro transformada num parque linear a alta cota, lugar de excelência para a caminhabilidade.

A mobilidade é um pilar estruturante, diria determinante na obtenção dessa qualidade de vida. Daí, o meu gosto e paixão em estudar a mobilidade urbana associada ao território, sempre numa perspectiva do "espaço público "como fio condutor de todo o sistema urbano. E mobilidade na sua visão holística tem de irrigar todos os tecidos urbanos. Cada vez entendo mais a cidade como um tecido em que os vasos capilares o terão de irrigar.

E quando falamos em qualidade de vida das pessoas, falamos obrigatoriamente em qualidade do ambiente urbano. Queremos, exigimos e sonhamos que haja uma relação direta entre as pessoas e o seu espaço envolvente, plataforma onde cruzam as múltiplas deslocações urbanas. Se esta relação for efetiva teremos cidades mais sustentáveis, inclusivas e saudáveis.

Assim, se por um lado, o espaço público tem de garantir as deslocações casa/ trabalho e casa/ escola em segurança e conforto, por outro, tem de garantir lugares de estadia e repouso, de abrigo e contemplação, de felicidade e magia. O espaço público, referido por Jan Gehl como "a Vida entre edifícios", não pode ser apenas o espaço que sobra na cidade, tem de ser um espaço de e para todos, como garantia da condição universal do direito à mobilidade e do direito à cidade.

Esta perspectiva exige cada vez mais responsabilidade aos técnicos, mais dedicação de estudo e reflexão teórica e pratica, pela simples percepção que o seu limite ínfimo se esgota numa pedra preciosa para quem planeia e desenha cidades. E em ambas as escalas de planeamento ou de 


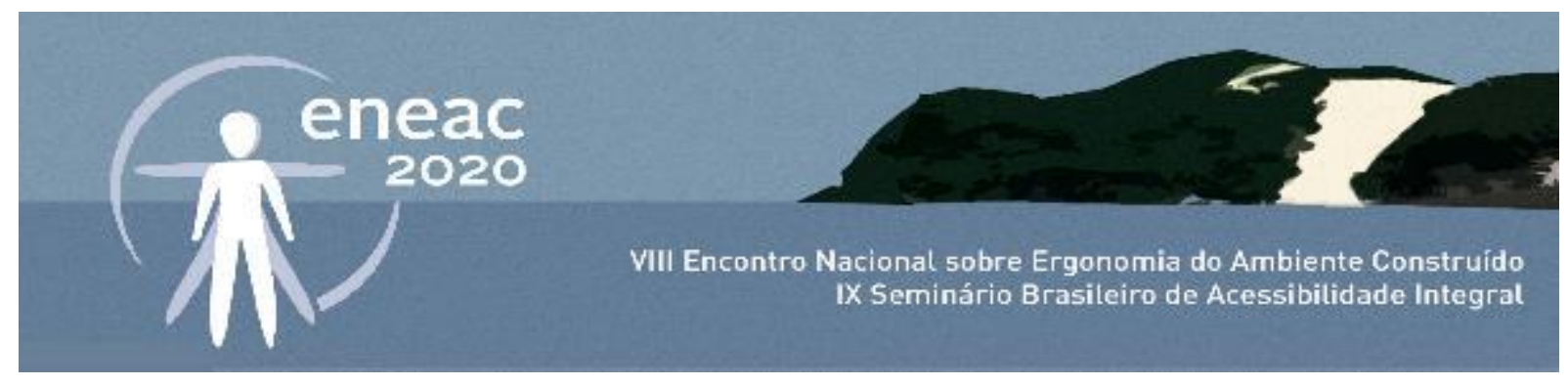

projeto, mais macro ou mais micro, a complexidade nas premissas técnicas e políticas exigem um esforço conjunto de todos os Stakeholders que desenham as cidades. Sim, porque o espaço público, o que sobrou, é mesmo muito reduzido e teremos de estabelecer prioridades na sua ocupação.

Este exercício diário e contínuo, resultante dos novos paradigmas urbanos estão a gerar novos padrões de mobilidade, e a nossa estreita relação com os municípios, exige cada vez conhecimento mais multidisciplinar e transversal.

É neste contexto, de coordenadora de uma equipa que tem trabalhado o planeamento da mobilidade urbana sustentável em diversas vilas e cidades portuguesas, e participado em vários fóruns mundiais, que aceitei, com todo o gosto, participar virtualmente do ENEAC2020 - VIII ENCONTRO NACIONAL DE ERGONOMIA DO AMBIENTE CONSTRUÍDO / IX SEMINÁRIO BRASILEIRO DE ACESSIBILIDADE INTEGRAL.

PALAVRAS-CHAVE: cidade, mobilidade, design, planejamento. 